\title{
THE CONTENT OF OCHRATOXIN A IN MOLDAVIAN WINE PRODUCTS
}

\author{
Boris Găină $^{1}$, Rodica Sturza ${ }^{2}$, Violeta Bejan ${ }^{2}$, Constantin Bodean ${ }^{1}$ \\ Moldavian Academy of Science ${ }^{l}$, Technical University of Moldova ${ }^{2}$ \\ E-mail: sturzar@yahoo.com
}

\begin{abstract}
The basic objective of this work is studying the content of ochratoxin A (OTA) in grapes, grape juice, and wine. This is an analysis of their origin, the conditions of contamination and ways decontamination, toxiconogenes mushrooms, toxicity, world and European regulations. It was estimated the methods of detection of mycotoxins in wine products. It has examined the contents of OTA in the moldavian juice/wine from different varietals at different stages of winemaking and obtained by different proceeds winemaking.
\end{abstract}

Keywords: mycotoxin, OTA, wine, grape juice.

\section{Introduction}

The United Nations Food and Agriculture Organization (FAO) estimates that about $25 \%$ of world production of food is contaminated by mycotoxins and the burden of mycotoxins causes the loss of nearly 1000 million tons of food each year. Mycotoxins may be listed without our knowledge in our everyday dishes [1].

On completion of toxicological tests, the OTA has been shown nephropathy, carcinogenic, teratogenic and immunosuppressive and was listed in the list of dangerous molecules [14]. Several human diseases attributed to this mycotoxin, such as kidney disease endemic countries in the Balkans and tumors of the urinary tract and kidney observed in Tunisia and Egypt and the detection of this molecule in the blood of healthy individuals or not around the world have shown great danger and the large exposure of humans to this mycotoxin. If the air and building materials are recognized as agents of exposure to this molecule food remains the main vector of contamination.

Whether in the animal or plant products, different levels have been detected. The products from the cereal sector are the most contaminated and participate for 50 to $80 \%$ by ingestion of OTA by men. The contamination by OTA products in the pipeline grape has been detected in 1996. This path is then ranked 2nd after the cereal sector for its contribution to the ingestion of human OTA estimated at $15 \%[14,15]$. The factors influencing OTA production are:

- OTA formation in grapes is mainly due to berry contamination by certain mould species, belonging essentially to the black Aspergillus species (in particular Aspergillus carbonarius species and to a lesser extent Aspergillus niger), but also to Penicillium species in cool temperatures regions;

- The growth of these molds occurs at air humidity levels of $72 \%$ to $90 \%$ and temperatures of $12^{\circ} \mathrm{C}$ to $39^{\circ} \mathrm{C}$ (optimum $28^{\circ} \mathrm{C}$ );

- The presence and spread of such fungus in vineyards are influenced by:

- environmental and climatic factors (high humidity, hot and dry environments)

- nocturnal dampening condition of grapes

- grape bunch shape

- aeration level of grape bunch

- susceptibility of vine varieties

- health status of grapes and berry injuries which are the main entry points for ochratoxinogenic fungus

- skin thickness

- use of fungicides

- winemaking procedures

- Damaged berries by Lobesia Botrana (worm grape).

Some importing countries have introduced restrictions on the content of mycotoxins and particularly of OTA in wines [5,15]. It is known that the European Union (EU) has already set a maximum limit of $2 \mu \mathrm{g} / 1$ of OTA in wine (red, white and rose) and other beverages based on mash of wine and / or grape. This limit applies to products from the 2005 harvest. Other countries, like Canada refuses imports of wine with more than $1 \mu \mathrm{g} / \mathrm{l}$ of ochratoxin A.

Requests for the harmless of wine products are becoming more stringent, limits or permissible concentrations of different toxins increasingly reduced, which requires that the source of an outbreak are considered multilaterally and complexity. That is why it is necessary to know this toxin (structure, properties, and regulatory acts) to study the sources of mycotics pollution, molds that attack vines producing OTA and for the development of processed effective prevention of the occurrence of toxins, complete decontamination or decrease the concentration under the permissible limits of international mash of wine and wine. In a context of increased competition, consideration of this very important issue by all wine is a priority. 
In this context the study of mycotoxins in wine is very current and important, particularly by the fact that their toxicity has been demonstrated and we must know our wines to be exported.

Two vilifications technology were studied to monitor the OTA throughout the winemaking: the white wine and red. The purpose of the study was to determine the concentration of OTA in wine products at different stages of winemaking. It focused on the analysis of samples of reds: Cabernet Sauvignon, Merlot, Pinot noir, Lidia, Bastard and those white Feteasca, Muscat, Saperavi.

\section{Materials and Methods}

The analytical methods for OTA determination in foodstuffs are $[9,13]$ :

- AOAC-2001.01IAC-HPLC with fluorescence detection

- CEN - EN 14133:2003

- MA-F-AS315-10-OCHRAT

- ELISA quantitative method

- Screening method (strip, yes/no response).

Moldovan wines in the detection of OTA done in the laboratory of the National Center for Quality of Wines by the enzymatic method with quantitative spectrophotometrical $(650 \mathrm{~nm})$ detection (ELISA quantitative method) $[3,4]$. It applies to the reds, whites, roses and the special wines and beer in the concentration limit of $0,2-25 \mu \mathrm{g} / 1$ (ppb). In the situation of higher concentrations are diluted samples in accordance with the instruction. The detection limit is $0,1 \mu \mathrm{g} / \mathrm{l}$, the limit of quantification of $0,2 \mu \mathrm{g} / \mathrm{l}$. This method can be applied to the determination of OTA in sparkling wines and sparkling after a PMD.

The principle of this method is a test immunosorbent directly connected with enzymes (CD-ELISA), which allows to obtain accurate concentrations in parts per billion (ppb). Ochratoxin samples and control substances involved together with other enzymes for places Liaison antibodies. After washing, adding the substrate, this reacts with the substance combined process accompanied by the appearance of the color blue. The intensity of color is inversely correlated with the content of the OTA in the sample. The results of this test are discussed in a micro alveolus for checking optical densities. The optical densities of control samples are the standard curve, to calculate the exact concentrations of OTA for tests.

This procedure is automated; the calculation is done directly by the Neogene-VERATOX device that presents information in the form of an analyst with the Packing of the curve indicating the contents of the OTA and fidelity of this test. For red wine is made sedimentation tannins with a special set Veratox.

For this study 22 samples of juice, mash of wine, and wine were analyzed. It was selected wines of our republic in dependence of the following criteria:

- by color

- depending on the contents of residual sugar

- $\quad$ Manufacturing Technology

Depending on the color used on a juice/must/white wine and red, while the manufacturing technology of sparkling wine and alcoholic dessert. Regarding the content of residual sugar and wine taste dry and semisweet were analyzed.

The absolute difference of two results of independent analysis conducted on identical material, using the same equipment in a short period of time not exceeding the limit $\mathrm{r}$ repetition more than $5 \%$ of all cases.

\section{Results and Discussions}

In the world we know more than 1000 species of fungi that grow on different parts of the vine. With us this number is reduced is less is more than 400 species. The microflora exchange dependence on environmental conditions, climacteric, the system of protection against disease and insects, agricultural technology used [2]. Macroclimate thus has a significant impact on the burden and fungal contamination OTA grapes.

In addition to the factors temperature, humidity and rainfall, the composition of sugar and acidity of the grapes direct substrate are critical factors in the mycotoxinogenesis.

Moldova has a temperate continental climate with a slight influence sea view near the Black Sea. The winters are cold, relatively mild in the south, with average temperatures ranging between - 3 - 5 degrees $\mathrm{C}$ in January. Summers are hot and sunny: the average temperature exceeds $20^{\circ} \mathrm{C}$ in July to about $40^{\circ} \mathrm{C}$. The summer heat is tempered by a strong breeze blowing an almost permanent south-east. So the temperature is optimal for the development of fungi. Aspergillus ochraceus is developing moderate temperatures ranging between 8 and $37^{\circ} \mathrm{C}$ with an optimum between 24 and $37^{\circ} \mathrm{C}[6]$.

Another factor favoring the development and growth of mold is moisture. In our rainfall is low and irregular. The average rainfall per year is $450 \mathrm{~mm}$ in the south, $560 \mathrm{~mm}$ in the center and $680 \mathrm{~mm}$ in the north. The availability of water combined with other favorable factors is sufficient to result in the emergence and development of fungi producing OTA. 
There are generally two types of risk: the risk biological and chemical hazards. Biological hazards are due to uncontrolled development of living organisms. The prevention of risks of contamination by microorganisms is an important issue for all players in the wine industry. The case of OTA is an example.

In the literature review conducted earlier, it was a synthesis of multiple factors that influence the content of OTA in wine products $[6,7,11]$. Some of them are interested for us that are why the part of this test was examined. It was interesting to know the content of the toxin for different types of wine at different stages of winemaking, the role of certain technological processes as well as the health cluster, sort of harvest, developments during the OTA the conservation of bottled wines.

The comparative content of OTA in certain wine products*

\begin{tabular}{|c|l|c|}
\hline $\mathrm{Nr}$ & Witness & OTA content in $\mu \mathrm{g} / \mathrm{l}(\mathrm{ppb})$ \\
\hline 1 & white grape juice & 0.1 \\
\hline 2 & red grape juice & 2.6 \\
\hline 3 & Muscat mash of wine & 0.5 \\
\hline 4 & Cabernet mash of wine & 3.0 \\
\hline 5 & Merlot row material & 0.5 \\
\hline 6 & Muscat & 0.3 \\
\hline 7 & Muscat Blanc & 0.1 \\
\hline 8 & Feteasca & 0.1 \\
\hline 9 & Saperavi & $>2$ \\
\hline 10 & Sangria & 0.12 \\
\hline 11 & Merlot & $<0.1$ \\
\hline 12 & Cabernet-Sauvignon & 0.9 \\
\hline 13 & Bastard & $>2$ \\
\hline 14 & Lidia & 0.4 \\
\hline 15 & Zemfira & 0.2 \\
\hline 16 & Rosu de Etulia & $<0.1$ \\
\hline 17 & Chardonnay dry wine & $<0.1$ \\
\hline 18 & Pinot dry wine & 0.5 \\
\hline 19 & Semisweet wine Chardonnay & $<0.1$ \\
\hline 20 & Kahor & 0.6 \\
\hline 21 & Sparkling Wine & 0.1 \\
\hline$* r=0,982$ & \\
\hline
\end{tabular}

Our study was proposed to determine the degree of contamination by OTA Moldovan wines. Following this analysis has been obtained very important and surprising. The data obtained are presented in the table 1 . The maximum of OTA content $(3 \mu \mathrm{g} / \mathrm{l})$ was detected in the must from the red grape Cabernet Sauvignon. In the majority of witnesses studied the minimum level of the toxin did not exceed $0,1 \mu \mathrm{g} / \mathrm{l}$. We can conclude that our wines are not beyond the maximum permissible ochratoxin A in all types of wine, but also drinks made from wine or grape, grape juice and ingredients based juice grapes, $2 \mu \mathrm{g} / 1$, set by the Regulation of the European Commission in 2005. This fact once again demonstrates that the Moldovan wines are harmless. So we can conclude that the wines of our Republic can compete with New World wines (Chile, Argentina, New Zealand, Australia, etc.) regarding this health problem [9-11].

One of our goals was to establish the content of the mycotoxin at different stages of winemaking evolution of OTA during the red wine which is presented below (Figure 1).

The evolution of OTA during the red winemaking includes five steps:
1: from veraison to mature;
2: after a few days of maceration;
3 : at the end of fermentation;
4: at bottling ( 3 months after completion ALF and collage FML + + filtration);
5: stage after bottling.

The concentration of the mycotoxin has been studied in grapes and wine and its evolution from veraison until bottling.

The first step includes the ripening period until maturation. The OTA may appear very early on grape (30 days before harvest). During this period there was a reduced level of OTA. The fungus is installed on grape berries 
damaged, develops preferentially at the heart of clusters, and it continues to harvest. 15 days before harvesting the concentration of the toxin begins to increase the award of costs of the must.

The second period is that of obtaining the must charge until maceration for 15 days. It is observed that the wine fermentation reached a level close to the maximum OTA because of existing factors that promote its extraction.

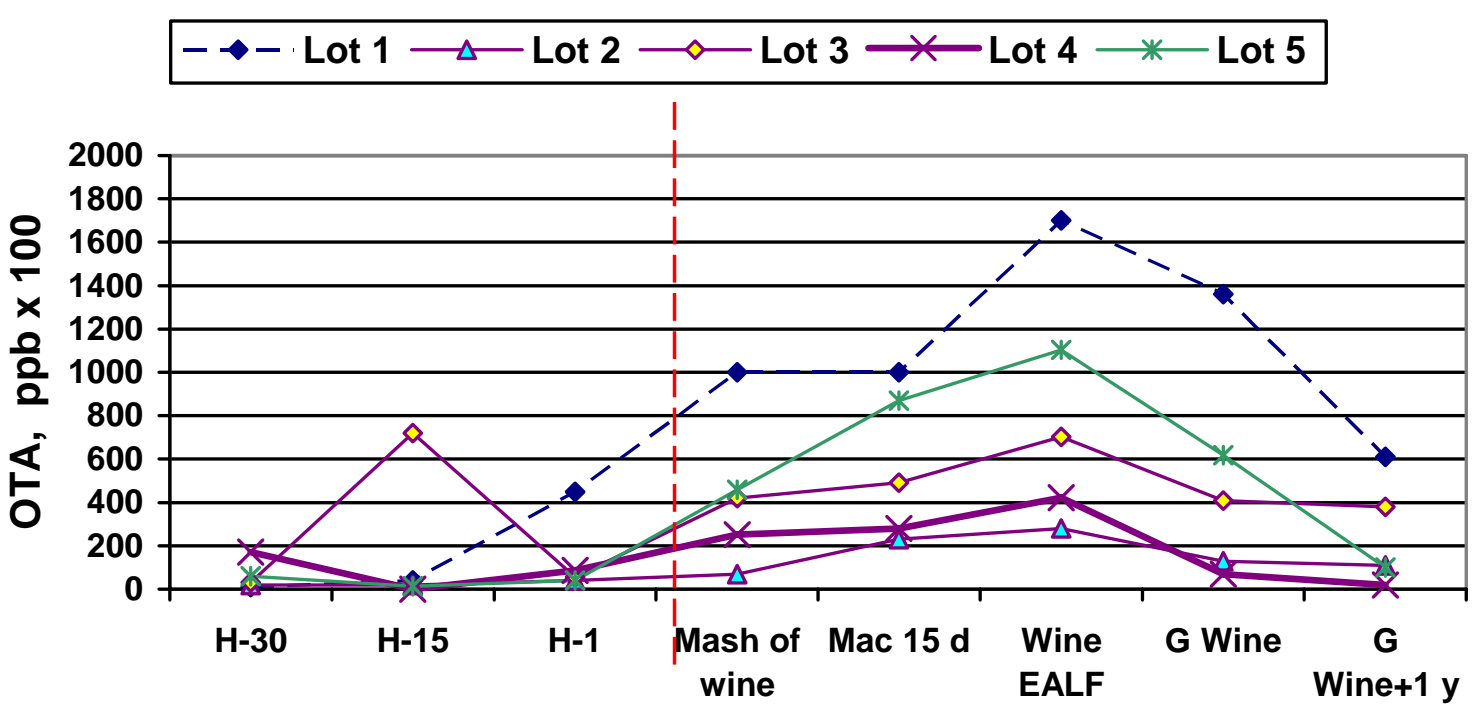

\section{Steps of winemaking}

Figure 1. OTA content evolution during the winemaking of red wine

The third stage is the end of the fermentation (ALF) when OTA reached a maximum. The fourth step is bottling (3 months after completion ALF and collage FML+filtration), OTA has decreased by 39\% on average. We can conclude that the collages are made effective in lowering the content of the mycotoxin.

The last step is after bottling and storage for a year. OTA content seems to diminish after bottling what makes us think that during the breeding OTA migrates in the filing.

Thanks to research that has been able to make the comparison between the content of the OTA in various alcoholic beverages and raw materials necessary for obtaining beverage was analyzed. In the first study it was determined the OTA in white grape juice and red in the must obtained from a white and red grape and wine in a white and red. The varieties were studied Muscat, Merlot and Cabernet Sauvignon. It was observed that the content of OTA is highest in juice, must and red wine, the maximum being prepared for the must Cabernet $(3 \mu \mathrm{g} / 1)$, so the reds are more susceptible to contamination.

In this study we have concluded that red wine is more contaminated by the toxin than white what has demonstrated the truthfulness of theoretical data available so far on this subject. The red wine requires a skin maceration that occurs before and during fermentation. The white wine this process completely excludes. This study confirms the work [11], that the OTA on this film, is found more easily in winemaking where maceration are important. The maceration process is a physical rather than chemical based on the extraction, distribution and adsorption which consists of maintenance of solids and liquids in contact for some time in certain conditions. It is likely that toxins on the solid berries are extracted in the juice along with the color, tannins and aromas. That is why OTA quantities are larger in red wine than in white or rose wines. The high contamination red mash of wine is also explained by the presence of conditions favorable for the development of mushroom toxin. The temperature and humidity play a role on growth, development and physiology of mushrooms. Aspergillus ochraceus indeed develops at moderate temperatures ranging between 8 and $37^{\circ} \mathrm{C}$ with an optimum between 24 and $37^{\circ} \mathrm{C}$, temperatures existing during the process of maceration.

To make a more complex analysis of wine we used as samples of grapes from different species of wine from various groups: Eurasian Group (Vitis vinifera) and group of North America (Vitis labrusca). Vitis vinifera is represented by Muscat Blanc, Merlot, Cabernet-Sauvignon. The varieties of Vitis labrusca group studied are: Lidia, Zemfira. The result turns to the wines made from Vitis labrusca have a higher content OTA from $2 \mu \mathrm{g} / 1$ than Vitis vinifera (Table 1).

The conservation of bottled wines is reflected by a decline in toxin by processes known and poorly studied. Several samples were used; the conclusion is that the content in bottled OTA decreased each wine (red or white wine). The average decrease is higher than $40 \%$. 
The results suggest that there is a continuous decline of the toxin from up to the end of vinification. The OTA who "disappeared" on the wine bottle is found mostly in the filing it is probably precipitated or adsorbed by the compounds that make up the deposit. The failure to find any deposit in the OTA initially present in the wine comes, probably, the difficulty of the determination of mycotoxin in the filing. While the bulk of the decline in the OTA on wines is reflected in the deposit, the runway part of its metabolism is not excluded.

The red grape juice shows that the content is higher - 2,6 ppb, but it is less compared to the mash of wine. Among the factors favoring the production of the toxin is the states of maturity at which the grapes were crushed, his health status, sort of harvest (Figure 2). In this context, we can mention that the sorting of the grapes is a process not commonly practiced in enterprises with Moldovan wine.

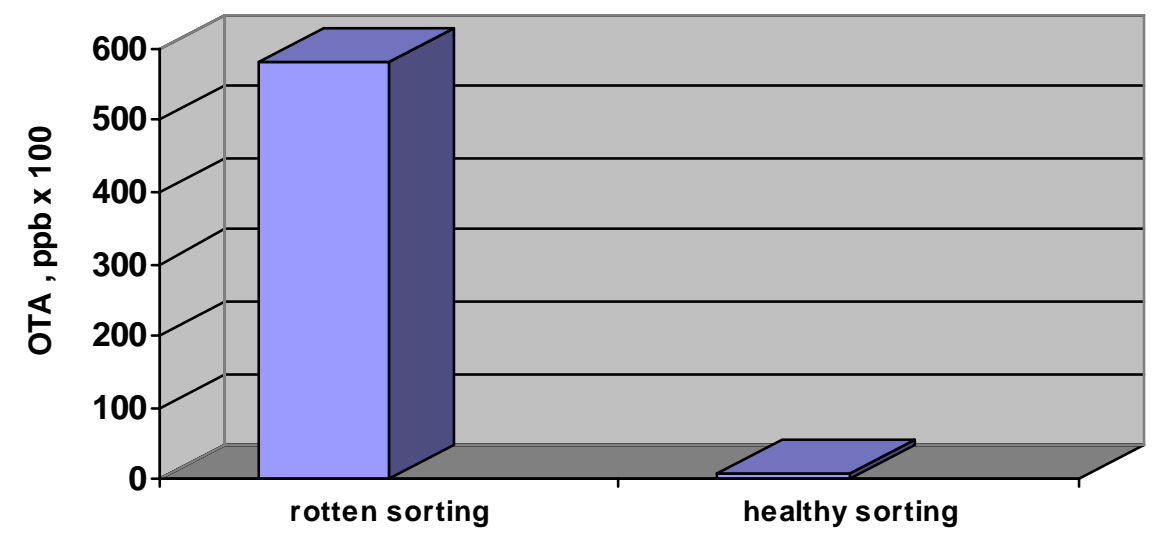

Figure 2. Content of the OTA in wines from the rotten sorting and healthy sorting

The ill health of the grapes is considered the main factor for the development of OTA in wine. A rotten harvest does not provide optimal security products. There is evidence that a high contamination of grapes by OTA involves a heavy contamination of wines produced. The master plant becomes a priority for the development of healthy wine with levels limits OTA. With the increasing maturity of grapes increases the risk of contamination with OTA and if the grapes are in a bad health risk becomes higher (Figure 3).

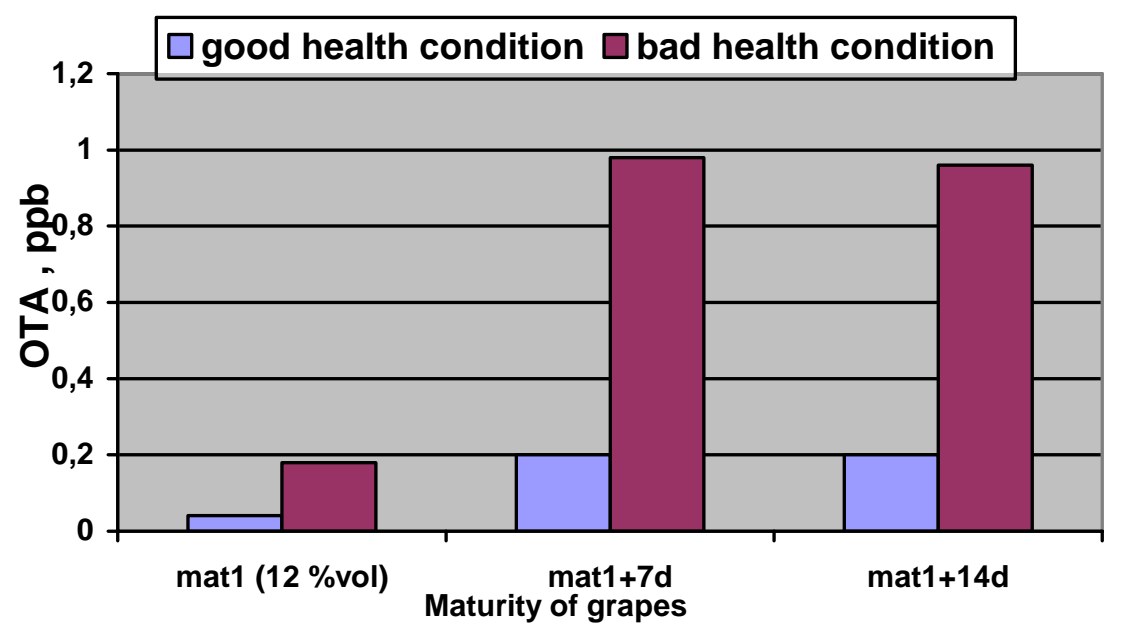

Figure 3. Impact of health status and level of maturity of grapes on the contamination of wines in OTA (ICV data on 84 wines)

This work took aim studying the content of OTA in different types of wines. The dry wine and white grape semisweet of Chardonnay and Pinot noir red were also discussed the purpose of determining the dependency of the presence/absence of residual sugar and the concentration of toxin. From table 1, we find that the content is $0,1 \mu \mathrm{g} / 1$ corresponding to the regulation, both for red wines than for whites. This allows us to say that the residual sugar is not a factor influencing the emergence and development of fungi producing toxins. The dry wine Pinot noir is the most contaminated $(0,5 \mu \mathrm{g} / \mathrm{l})$ but yet its content does not exceed the permissible level of OTA. The content of the OTA in wine is generally lower than in must by the fact that the content in the bottle decreases. 
According to literature reviews found that among the factors influencing the presence of the toxin: temperature, humidity, type of substrate, and is the gaseous composition. Technology sparkling wines requires the formation of $\mathrm{CO}_{2}$ content is very low, we can assume that this is probably the pressure and the presence of $\mathrm{CO}_{2}$ gas that affects the content of the OTA. It is already known that the formation of this toxin is inhibited to $30 \% \mathrm{CO}_{2}$.

Regarding the presence of alcohol, conducted according to a convex model, there is a significant inhibition of growth from a concentration of 2\% ethanol. From 1 until 3\% of ethanol production is stimulated and OTA has achieved the most important values to the concentration of $2 \%$ or an increase of 6 times for Aspergilius carbonarius Mu243 and 13 times for Aspergilius niger G731. Beyond 3\% inhibition of total production of OTA was observed. The fermentation, implemented in the manufacture of wine, is deteriorating largely OTA present in grape juice or cereals used. OTA content decreases by $35 \%$ on average during the fermentation.

The yeast fermentation ensuring adsorption capacity of OTA more or less important depending strains. Tests in 2004 showed that the adsorption was higher in musts contaminated red white. The 2005 results confirm that over a yeast adsorb the color of it adsorb OTA. A choice in the strain of yeast is possible. These differences between yeast are significant red wine; one possible explanation is that the polyphenols may interact with these phenomena adsorption. Different groups of yeast have been identified, some of whom may trap 30\% of OTA, further to $57 \%$.

However, it is unclear today what the metabolites from this are and what stages of fermentation process occurs degradation. Such knowledge is essential to determine the dangers associated with the presence of the OTA in musts: they are not necessarily restricted to OTA remaining in the wine, but may also include those related to metabolites of degradation.

Regarding the malolactic fermentation research is needed because we do not know until now its influence on the evolution of the content of the toxin.

\section{References}

[1] Pfohl-Leszkowicz. Les mycotoxines dans l'alimentation. Evaluation et gestion du risque. Conseil supérieur d'hygiène publique de France, coord. Paris: 1999, pp. 3-14, 17-30, 141-169, 409-427.

[2] Gaina, B. Biotehnologii ecologice viti-vinicole, Chisinau, 2007, pp. 34-37.

[3] Gaina, B.; Sturza, R.; Bejan, V. Ochratoxina A- una dintre toxinele din vinuri, Viticultura si vinificatia in Moldova, 2007, 5(11), pp. 19-20.

[4] Cutzach-Billard. Etude comparative d'une methode semi-quantitative pour la détection de l'Ochratoxine A, Revue des œnologues, 2006, 121, pp. 43-45.

[5] Dumoulin, M., Riboulet, J. M. Réflexions sur la présence d'ochratoxine A dans les vins et les jus de raisin. Revue Française d'œnologie, 2002, 104, pp. 11-13.

[6] Esteben, A., Abarca, M. L., Bragulat, M. R. Cabanes, F. J. Effects of temperature and incubation time on production of ochratoxin A by black aspergilli. Research in Microbiology, 2004, 155, pp. 861-866.

[7] Fleet, G. H. Yeast interactions and wine flavour. International Journal of Food Microbiology, 2003, 86, pp. 1122.

[8] Höhler, D. Ochratoxin A in food and feed: occurrence, legislation and mode of action. Z Ernahrungswiss, 1998, 37, pp. 2-12.

[9] Merkaki, P., Delpont-Binet, C., Grosso, F., Dragacci, S. Determination of ochratoxin A in red wine and vinegar by immunoaffinity high-pressure liquid chromatography. Journal of Food Protection, 2001, 64, 533537.

[10] Pretet -Lataste, J-L Berger, B. Molot. Analyse du risque dans les vins: l'exemple de l'Ochratoxine A, Revue des œnologues, 2006, 119, pp. 43-45.

[11] Ramos, A. J., Sanchis, V., Marin, S. Incubation time and water activity effects on ochratoxin A production by Aspergillus section Nigri strains isolated from grapes. Letters in Applied Microbiology, 2004, 38, pp. 72-77.

[12] Rouseau, J., Blateyron, L. Ochratoxine A dans les vins: pas de solution curative dans les vins, priorite a la maitrise sanitaire au vignoble. Revue des CEnologues, 2002, 104, pp. 14-16.

[13] Visconti, A., Pascale, M., Centonze, G. Determination of ochratoxin A in wine by means of immunoaffinity column clean-up and high performance liquid chromatography. Journal of Chromatography A, 1999, 864, pp. 89-101.

[14] WHO. Evaluation of certain mycotoxins in food. Fifty-sixth report of the joint FAO/WHO expert committee on food additives. WHO technical report series, Geneva, 2002, 906, pp. 27-28.

[15] Varga, J., Kevei, E., Rimyu, E., Teren, J. \& Kazakiewicz, Z. Ochratoxin production by Aspergillus species. Appl. Environ. Microbiol., 1996, 62, pp. 4461-4464. 